\title{
OPEN Determination of thresholds of risk in women at average risk of breast cancer to personalize the organized screening program
}

\begin{abstract}
Emmanuel Bonnet ${ }^{1,2}$, Jean-Pierre Daures ${ }^{1,2} \&$ Paul Landais $^{1}$
In France, more than 10 million women at "average" risk of breast cancer (BC), are included in the organized $\mathrm{BC}$ screening. Existing predictive models of $\mathrm{BC}$ risk are not adapted to the French population. Thus, we set up a new score in the French Hérault region and looked for subgroups at a graded level of risk in women at "average" risk. We recruited a retrospective cohort of women, aged 50 to 60 , who underwent the organized BC screening, and included 2241 non-cancer women and 527 who developed a BC during a 12-year follow-up period (2006-2018). The risk factors identified were high breast density (ACR BI-RADS grading)(B vs $A$ : $H R=1.41,95 \% C l[1.05 ; 1.9], p=0.023 ; C$ vs $A: H R=1.65$ [1.2; 2.27], $p=0.02 ; D$ vs $A: H R=2.11$ [1.25;3.58], $p=0.006)$, a history of maternal breast cancer (HR = 1.61 [1.24; 2.09], $p<0.001)$, and socioeconomic difficulties (HR 1.23 [1.09; 1.55], $p=0.003)$. While early menopause (HR $=0.36[0.13 ; 0.99], p=0.003)$ and an age at menarche after 12 years $(H R=0.77[0.63 ; 0.95], p=0.047)$ were protective factors. We identified 3 groups at risk: lower, average, and higher, respectively. A low threshold was characterized at $1.9 \%$ of 12 -year risk and a high threshold at 4.5\% 12-year risk. Mean 12-year risks in the 3 groups of risk were $1.37 \%, 2.68 \%$, and $5.84 \%$, respectively. Thus, $12 \%$ of women presented a level of risk different from the average risk group, corresponding to 600,000 women involved in the French organized BC screening, enabling to propose a new strategy to personalize the national BC screening. On one hand, for women at lower risk, we proposed to reduce the frequency of mammograms and on the other hand, for women at higher risk, we suggested intensifying surveillance.
\end{abstract}

Breast cancer is the most common cancer in women and the leading cause of death from cancer in women in France $^{1}$. The earlier breast cancer is detected, the greater the chances of recovery. For a breast cancer detected at an early stage, 5 -year survival is $99 \%$, and $27 \%$ for a metastatic cancer ${ }^{2}$. The difference in the detection stage also influences the cost of medical care ${ }^{3}$. While high risk women ${ }^{4}$ including women with a deleterious constitutional mutation predisposing to breast cancer, women for whom a surgical intervention with biopsy has shown an histological risk factor as well as women with a personal history of breast cancer receive an individualized monitoring, the majority of women aged from 50 to 74 are included in the nationwide organized breast cancer screening. In France, this screening consists of a mammography (2 views) every two years with a double reading of mammographic images, and targets a population of more than 10 million women ${ }^{5}$. Current participation is about $50 \%$ with a target of $65 \%$. The number of women actually screened in France is therefore between 5 and 6.5 million.

In April 2017, the Ministry of Health published an action plan to renovate the organized breast cancer screening ${ }^{6}$ based on the recommendations of the National Cancer Institute and at the request of the women interviewed during the citizen consultation to determine the levels of risk for the population at "average" risk ${ }^{7}$. This reorganization plan aimed to enable a more personalized organized screening, and encouraged research projects on tools and methods for assessing the level of risk, including scoring. The aim of our study was to explore whether, among the 10 million women at "average-risk" targeted by the French organized screening, some women would be at lower-risk than average risk and others at higher risk. The aim of this personalized organized screening is to optimize the available resources to make screening as efficient as possible. As it was a

\footnotetext{
${ }^{1}$ Montpellier University, EA2415, Institut Universitaire de recherche clinique, 34093 Montpellier Cedex 5, France. ${ }^{2}$ Languedoc Mutualité, Nouvelles Technologies, AESIO, Montpellier, France. ${ }^{\boxplus}$ email: emmanuel.bonnet@ umontpellier.fr
} 
request from the women interviewed during the citizen consultation, it could also make them more involved in organized breast cancer screening and increase the participation rate.

Several predictive models already exist, such as Gail ${ }^{8}$, BRCAPRO $^{9}$, BODICEA $^{10}$, Tyrer-Cuzick $^{11}$, or PROCAS ${ }^{12}$ models. But they are not adapted to some European populations ${ }^{13}$ and most of them include BRCA1 and BRCA2 mutations. However, in France, women presenting with these mutations are not included in the organized nationwide screening and, as explained in PROCAS ${ }^{12}$, mutations in breast cancer genes such as BRCA1 and BRCA2 are too infrequent to affect risk prediction appreciably in the models for the general population. Moreover, it is difficult to estimate an individual risk precisely ${ }^{14,15}$.There are also some studies on European populations performed in England ${ }^{12}$. We, therefore, intended to set up a new risk model, including new variables, adapted to the French population, and enabling to explore whether in this average risk population it was possible to identify women at lower risk of breast cancer (or higher risk, respectively) in order to adapt the organized screening accordingly by proposing a different organized screening strategy depending on the level of risk identified.

\section{Material and methods}

Database. We used the database of the Center that coordinates breast cancer screening (CRCDC-OC) in the Hérault department, France. This database registers women with precise, verified, and consolidated information on the occurrence of breast cancer during the follow-up of their screening. The data are also consolidated by the Hérault tumor register which provides an exhaustive information on the occurrence of breast cancer, including interval cancers during the follow-up period. We enrolled women, aged 50 to 60 at inclusion, who experienced a 12 -year breast cancer screening from 2006. We extracted a database of 33,858 women, including 805 women who developed a breast cancer in 3-12 years following inclusion. We did not include women who have been diagnosed with breast cancer during the first two years of follow-up to avoid including women who might have already developed a cancer prior to inclusion, but not yet diagnosed at inclusion. Data were recovered by a telephone survey. It was not possible to interview 33,000 women. Therefore, on one hand we selected all the women who developed a breast cancer during the follow-up period, and on the other hand, we randomly selected 5000 women among those who did not develop breast cancer using the sample function of the R software applied to the list of 32,962 unique identifiers.

Power. We hypothesized a risk ratio $\geq 2$, with a ratio of 4 to 1 between women who did not develop breast cancer and those who did during the follow-up period, together with a power of $80 \%$. It gave a required sample size of 543 women with breast cancer during the follow-up period and 2174 women without breast cancer.

Study questionnaire. We looked for the risk factors for breast cancer in average risk women reported in the literature prior to creating the study questionnaire. We elaborated a text mining algorithm-assisted search (TEMAS) (available at shiny.temas-bonnet.site) to optimize the bibliographic search on very large volumes of scientific articles. We also included the variables used in Gail's model relative to women at average risk. The study questionnaire is provided in Supplementary material 1.

Data collection. Data were collected by telephone by two trained investigators. An explanatory leaflet (Supplementary material 3) was sent to all participants prior to the phone call and informed consent was obtained from all individual participants prior to the telephone interview. Responses to the study questionnaire were collected between November 2018 and May 2019. The inclusion flowchart is shown on Figure 1; 2,198 women were unreachable (mostly unassigned phone number, or reiterated unanswered calls) and 530 refused to participate (mostly alleging lack of time). Thus, this survey enabled collecting 3077 questionnaires, including 597 questionnaires from women who developed a breast cancer. The Case Report Form was developed with the ACCESS software. The analysis database was provided by the CRCDC-OC while having anonymized the data beforehand. This study complies the MR003 CNIL's (National Commission for Informatics and Liberties) methodology (Declaration: 2200402v0). The study was also agreed by the ethics committee of the Personal Protection Committee (A0246039). All methods were performed in accordance with the relevant guidelines and regulations.

Statistical analysis. Data management was performed on the fly. A data check was performed daily, especially on outliers and missing data. It enabled to call back women without delay if needed. Statistical analysis was carried out using R software ${ }^{16}$.

Descriptive analysis. We discretized the variables according to the literature. For duration of oral contraceptive ${ }^{17}$ we retained the classes 0, [1,5[, [5,10[, and $\geq 10$. For the number of biopsies, we complied with Gail's classes ${ }^{8} 0$, $1, \geq 2$. Breast density was categorized in four classes according to the ACR BI-RADS (Breast Imaging-Reporting and Data System) Atlas ${ }^{18}:$ A: the breasts are almost entirely fatty, B: there are scattered areas of fibroglandular density, C: the breasts are heterogeneously dense, and D: the breasts are extremely dense. For the number of hours per week of physical activity we followed WHO recommendations ${ }^{19}: 0,[1-5[$, and $\geq 5$. Alcohol consumption (in glasses per week) was discretized as follows : $0,[1,10[, \geq 10$ according to Santé Publique France (French public health service) recommendations ${ }^{20}$. Age at menarche was divided as follow: $<12$ and $\geq 12^{21}$. Age at first live birth was discretized in 3 classes $^{22}$ : nulliparous, $\leq 24$, and $>24$. For number of children, we used the average number of children in the generation of interes ${ }^{23}: 0,[1,3[$, and $\geq 3$. For the total duration of breastfeeding we followed WHO and UNICEF recommendations ${ }^{24}: 0,[1,7[$, and $\geq \overline{7}$. For age at menopause, we used the definition of the national college of French gynecologists of early menopause ${ }^{25}:<41, \geq 41$. We created a socio-economic hardship binary variable based on the EPICES ${ }^{26}$ score. Women responded to the EPICES questionnaire, and 


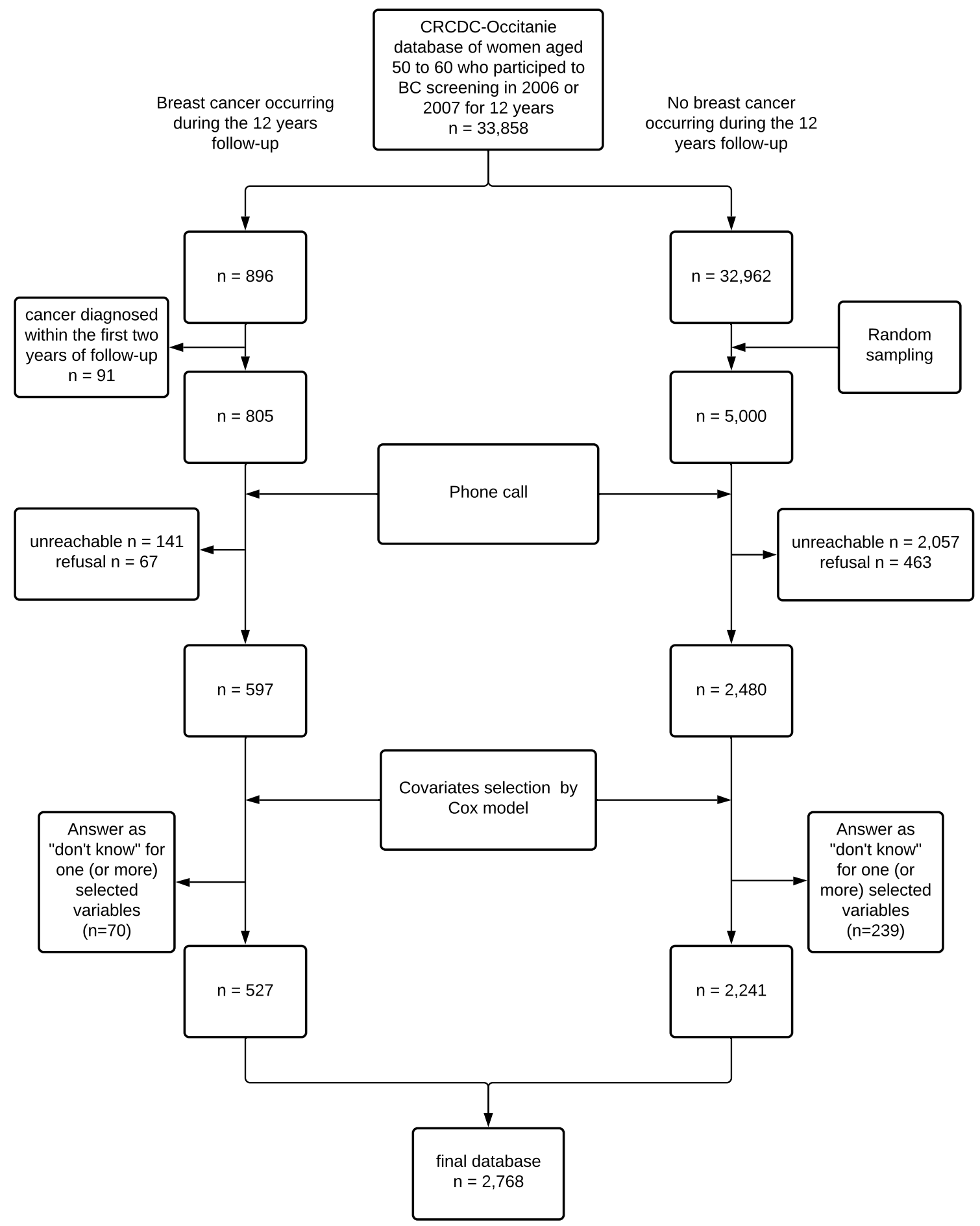

Figure 1. Flowchart of the retrospective cohort study.

we only kept the two covariates which were statistically significant in univariate models. The modalities of the binary covariate thus constructed were "yes" if the interviewee presented financial hardship and / or was not going on vacation, and "no" otherwise. We also studied overweight (i.e. BMI $\geq 25$ ). We also studied detailed family history of breast cancer : mother, sister, daughter, and aunt. All quantitative variables were also tested as continuous variables.

Cox model. All variables with a P-value $<0.2$ in the univariate models were included in a global Cox model, then a selection with the stepwise Akaiké information criterion (AIC) was achieved (age was forced in the model) in order to obtain $\hat{\beta}$, the estimated coefficients of the Cox proportional hazards regression model. Schoenfeld residuals were computed to check the proportional hazards assumption. 
Our goal was to define an individual score. Therefore, to estimate $\hat{\Lambda}_{0}$, the cumulative base-line hazard function, we used Breslow's estimator ${ }^{27}$ defined below.

$$
\hat{\Lambda}_{0}(t)=\sum_{i: T_{i} \leqslant t} \frac{d_{i}}{\sum_{j \in R\left(T_{i}\right)} \exp \left(\hat{\beta}^{\prime} Z_{j}\right)}
$$

with:

- $T_{1}<T_{2}<\cdots<T_{12}$ distinct times to event

- $d_{i}$ the number of events detected at $T_{i}$

- $Z_{i}$ the value of the covariates for patient $i$

- $R\left(T_{i}\right)$ all individuals still at risk at time $T_{i}^{-}$(just before $T_{i}$ )

- $\hat{\beta}$ the estimated coefficients of the Cox proportional hazards regression model

It enabled to estimate a risk function $F$ for each individual as a function of her covariates :

$$
\hat{F}(t \mid Z)=1-\hat{S}(t \mid Z)=1-\exp \left(-\hat{\Lambda}_{0}(t) \exp \left(\hat{\beta}^{\prime} Z\right)\right)
$$

Bootstrap. As we performed a random sampling among women without breast cancer, in our database, the distribution between women who developed cancer and the others was no longer representative of the starting population. To remedy this, we performed bootstrap samples. Bootstrap is a resampling method that uses random sampling with replacement. This method allowed to avoid skewing cancer rates compared to the population of interest without introducing bias. We computed 100,000 bootstrap databases using stratified random sampling with replacement among women for whom we obtained answers to all the covariates of the final Cox model, in order to obtain a database close to the initial CRCDC database (i.e. 33,858 women, including 896 who developed a breast cancer within the 12 years of follow-up).

In these databases, mean risk was identical to the one of the CRCDC database. Then, we estimated, for each woman, $\Lambda_{0}(t)$, and calculated $F(12 \mid Z)$ to obtain a risk score of developing a breast cancer during the follow-up period.

Thresholds and likelihood ratios. In France, the number of women actually screened is between 5 and 6.5 million. Among these women, we hypothesized that $10 \%$ of them might have a risk different from the "average" risk of breast cancer, either lower or higher. This average 12 -year risk was $2.6 \%$ in the organized screening population. From a clinical standpoint, we looked for women that might have a risk two times lower than this "average" risk. This group was considered as at lower-risk. We also looked for women that might have a risk two times higher than this "average" risk. This group was considered as at higher-risk. We then searched for the corresponding thresholds. We looked for $s_{1}$, the higher risk threshold, and $s_{2}$, the lower risk threshold, such as:

$$
\begin{aligned}
& \qquad \frac{\mathbb{P}(M \mid R>s)}{\mathbb{P}(M \mid R<s)} \geq 2 \quad \forall s \geq s_{1} \\
& \text { and } \\
& \quad \frac{\mathbb{P}(M \mid R<s)}{\mathbb{P}(M \mid R>s)} \leq 0.5 \quad \forall s \leq s_{2}
\end{aligned}
$$

where:

- M represents the event "developing a breast cancer during the 12 years follow-up";

- $\mathrm{R}$ represents the risk as determined by the score.

This method then enabled to delineate 3 groups according to the level of risk: lower risk, average risk, and higher risk.

Given that, for each threshold $s$, the likelihood ratios (LR) either positive (+) or negative (-) were as follows:

$$
\operatorname{LR}+(s)=\frac{\operatorname{sensitivity~}(s)}{1-\operatorname{sensitivity~}(s)} \quad \operatorname{LR}-(s)=\frac{1-\operatorname{sensitivity~}(s)}{\operatorname{sensitivity~}(s)}
$$

We plotted the curves LR+(s) and LR-(s) curves and looked for $s_{1}$ and $s_{2}$ according to the calculations available in Supplementary material 2.

Women with a risk score below the "low threshold" will be considered at lower risk of breast cancer, women with a risk level between "low threshold" and "high threshold" will be considered at average risk and finally, women with a risk score above the "high threshold" will be considered at higher risk of breast cancer in this population of women at average risk.

Ethics approval. We obtained the authorization No.: 2200402v0 from the CNIL's (National Commission for Informatics and Liberties). We also received the agreement (No.: A0246039) of the ethics committee of the 


\begin{tabular}{|c|c|c|c|c|}
\hline Breast cancer & & $\begin{array}{l}\text { No } \\
\text { n (\%) }\end{array}$ & $\begin{array}{l}\text { Yes } \\
\text { n (\%) }\end{array}$ & P-value \\
\hline \multirow{3}{*}{ Age (years) } & {$[49,53[$} & $626(25.2)$ & $156(26.1)$ & \multirow{3}{*}{0.164} \\
\hline & {$[53,57[$} & $915(36.9)$ & $196(32.8)$ & \\
\hline & {$[57,60]$} & $939(37.9)$ & $245(41.0)$ & \\
\hline \multirow{2}{*}{ Oral contraceptive use } & No & $605(24.5)$ & $165(27.7)$ & \multirow{2}{*}{0.111} \\
\hline & Yes & $1867(75.5)$ & $430(72.3)$ & \\
\hline \multirow{4}{*}{ Contraceptive pill duration of use (years) } & 0 & $605(24.8)$ & $165(28.5)$ & \multirow{4}{*}{0.156} \\
\hline & {$[1,5[$} & $520(21.3)$ & $127(21.9)$ & \\
\hline & {$[5,10[$} & $327(13.4)$ & $80(13.8)$ & \\
\hline & $\geq 10$ & $986(40.4)$ & $207(35.8)$ & \\
\hline \multirow{3}{*}{ Number of breast biopsies } & 0 & $2182(88.8)$ & $506(86.2)$ & \multirow{3}{*}{0.042} \\
\hline & 1 & $231(9.4)$ & $61(10.4)$ & \\
\hline & $\geq 2$ & $45(1.8)$ & $20(3.4)$ & \\
\hline Breast density & A & $338(13.6)$ & $60(10.1)$ & \multirow{4}{*}{0.012} \\
\hline \multirow{3}{*}{ (BI-RADS classification) } & $\mathrm{B}$ & $1483(59.8)$ & $348(58.3)$ & \\
\hline & $\mathrm{C}$ & $604(24.4)$ & $168(28.1)$ & \\
\hline & $\mathrm{D}$ & $55(2.2)$ & $21(3.5)$ & \\
\hline \multirow{3}{*}{ Physical activity (hours/week) } & 0 & $972(39.3)$ & $225(37.7)$ & \multirow{3}{*}{0.093} \\
\hline & {$[1,5[$} & $1185(47.9)$ & $275(46.1)$ & \\
\hline & $\geq 5$ & $318(12.8)$ & $97(16.2)$ & \\
\hline \multirow{3}{*}{ Alcohol consumption (glasses/week) } & 0 & $1329(53.6)$ & $344(57.7)$ & \multirow{3}{*}{0.16} \\
\hline & {$[1,10[$} & $920(37.1)$ & $197(33.1)$ & \\
\hline & $\geq 10$ & $229(9.2)$ & $55(9.2)$ & \\
\hline \multirow{2}{*}{ Age at menarche (years) } & $<12$ & $483(20.1)$ & $133(23.1)$ & \multirow{2}{*}{0.121} \\
\hline & $\geq 12$ & $1919(79.9)$ & $442(76.9)$ & \\
\hline \multirow{3}{*}{ Age at first live birth (years) } & $\leq 24$ & $1361(55.0)$ & $334(56.4)$ & \multirow{3}{*}{0.226} \\
\hline & $>24$ & $911(36.8)$ & $200(33.8)$ & \\
\hline & nulliparous & $201(8.1)$ & $58(9.8)$ & \\
\hline \multirow{3}{*}{ Number of children } & 0 & $245(9.9)$ & $72(12.1)$ & \multirow{3}{*}{0.068} \\
\hline & {$[1,3[$} & $1694(68.3)$ & $379(63.5)$ & \\
\hline & $\geq 3$ & $541(21.8)$ & $146(24.5)$ & \\
\hline \multirow{3}{*}{ Total duration of breastfeeding (months) } & 0 & $1383(55.8)$ & $343(57.6)$ & \multirow{3}{*}{0.026} \\
\hline & {$[1,7[$} & $739(29.8)$ & $149(25.0)$ & \\
\hline & $\geq 7$ & $355(14.3)$ & $104(17.4)$ & \\
\hline \multirow{2}{*}{ Overweight (BMI $\geq 25$ ) } & No & $2120(87.7)$ & 488 (85.2) & 0120 \\
\hline & Yes & $298(12.3)$ & $85(14.8)$ & 0.122 \\
\hline 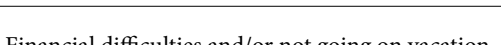 & No & $1518(61.9)$ & $323(54.8)$ & 0002 \\
\hline Financial difficulties and/or not going on vacation & Yes & $935(38.1)$ & $266(45.2)$ & 0.002 \\
\hline A sest mos & $\geq 41$ & $2229(94.1)$ & $532(95.3)$ & 0211 \\
\hline Age at menopause (years) & $<41$ & $139(5.9)$ & $26(4.7)$ & 0.311 \\
\hline 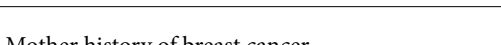 & No & $2251(92.4)$ & $517(87.9)$ & 0001 \\
\hline Mother history of breast cancer & Yes & $184(7.6)$ & $71(12.1)$ & 0.001 \\
\hline Sister history f brenct cancer & No & $2261(91.6)$ & $536(90.1)$ & 0268 \\
\hline & Yes & $207(8.4)$ & $59(9.9)$ & 0.268 \\
\hline 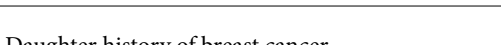 & No & $2451(99.1)$ & 588 (98.7) & 0 \\
\hline Daughter history of breast cancer & Yes & $23(0.9)$ & $8(1.3)$ & 0.499 \\
\hline Aunt hictory of brenctconcer 10 & No & $2271(93.9)$ & $521(91.2)$ & \\
\hline Aunt history of breast cancer & Yes & $148(6.1)$ & $50(8.8)$ & 0.029 \\
\hline
\end{tabular}

Table 1. Descriptive analysis.

CPP (Personal Protection Committee). All methods were performed in accordance with the relevant guidelines and regulations.

Consent to participate. An explanatory leaflet (Supplementary material 3) was sent to all participants prior to the phone call and informed consent was obtained from all individual participants prior to the telephone interview. 


\begin{tabular}{|l|l|l|l|l|}
\hline & Breast density & Unreachable or refusal & Answers & P-value \\
\hline \multirow{5}{*}{ No breast cancer } & $\mathrm{A}$ & $17.2 \%$ & $13.7 \%$ & \\
\cline { 2 - 4 } & $\mathrm{B}$ & $58.1 \%$ & $59.8 \%$ & \multirow{3}{*}{0.0007} \\
\cline { 2 - 4 } & $\mathrm{C}$ & $21.7 \%$ & $24.3 \%$ & \\
\cline { 2 - 4 } & $\mathrm{D}$ & $3.0 \%$ & $2.2 \%$ & \\
\hline \multirow{5}{*}{ Breast cancer } & $\mathrm{A}$ & $11.7 \%$ & $10.5 \%$ & \multirow{2}{*}{0.6035} \\
\cline { 2 - 4 } & $\mathrm{B}$ & $61.4 \%$ & $58.1 \%$ & \\
\cline { 2 - 4 } & $\mathrm{C}$ & $23.3 \%$ & $28.0 \%$ & \\
\cline { 2 - 4 } & $\mathrm{D}$ & $3.6 \%$ & $3.4 \%$ & \\
\hline
\end{tabular}

Table 2. Distribution of breast density according to the answer or not to the study questionnaire.

\begin{tabular}{|l|l|l|l|l|l|}
\hline & \multicolumn{2}{|l|}{$\begin{array}{l}\text { Unreachable } \\
\text { or refusal }\end{array}$} & \multicolumn{2}{|l|}{ Answers } & \multirow{2}{*}{ P-value } \\
\cline { 2 - 5 } & \multicolumn{2}{|l|}{ mean (sd) } & \multicolumn{2}{|l|}{ mean(sd) } & 0.384 \\
\hline No breast cancer & 55 & $(3.2)$ & 55.1 & $(3.2)$ & 0.325 \\
\hline Breast cancer & 55.7 & $(3.1)$ & 55.3 & $(3.3)$ & 0.125 \\
\hline
\end{tabular}

Table 3. Distribution of age according to the answer or not to the study questionnaire.

\begin{tabular}{|c|c|c|c|c|}
\hline & & Hazard Ratio & $95 \% C I$ & P-value \\
\hline Age & & 1.024 & $0.997-1.05$ & 0.084 \\
\hline \multirow{4}{*}{ Breast density } & A & - & - & - \\
\hline & B & 1.411 & $1.05-1.9$ & 0.023 \\
\hline & C & 1.651 & $1.2-2.27$ & 0.002 \\
\hline & $\mathrm{D}$ & 2.112 & $1.25-3.58$ & 0.006 \\
\hline \multirow{2}{*}{ Mother history of breast cancer } & No & - & - & - \\
\hline & Yes & 1.612 & $1.24-2.09$ & $<0.001$ \\
\hline \multirow{2}{*}{ Financial difficulties and/or not going on vacation } & No & - & - & - \\
\hline & Yes & 1.299 & $1.09-1.55$ & 0.003 \\
\hline \multirow{2}{*}{ Age at menopause } & $\geq 41$ & - & - & - \\
\hline & $<41$ & 0.364 & $0.13-0.99$ & 0.047 \\
\hline \multirow{2}{*}{ Age at menarche } & $<12$ & - & - & - \\
\hline & $\geq 12$ & 0.774 & $0.63-0.95$ & 0.015 \\
\hline Age at menopause $<41$ and Age at menarche $\geq 12$ & & 2.73 & $0.91-8.19$ & 0.073 \\
\hline
\end{tabular}

Table 4. Cox model for the occurrence of breast cancer. HR for Age at menopause $<41$ and Age at menarche $\geq$ $12=0.364 \times 0.774 \times 2.73=0.769$.

Consent for publication. Not applicable.

\section{Results}

Personalized organized breast cancer screening retrospective cohort: descriptive analysis. Descriptive analysis result is presented in Table 1 . The significant risk factors in the univariate analysis were the number of biopsies $(p=0.042)$, breast density $(p=0.012)$, total duration of breastfeeding $(p=0.026)$, financial difficulties and/or not going on vacation $(p=0.002)$, mother history of breast cancer $(p=0.001)$, and aunt history of breast cancer $(p=0.029)$.

We explored whether a selection bias might have occurred. We analyzed the distribution of the two variables (age and breast density) we had for women who could not be reached or who refused to answer our questions. The results are shown in Tables 2 and 3. The only significant difference was observed for breast density of women who did not develop cancer during the follow-up. Women who responded to the survey and did not present a breast cancer during the follow-up period, had a significantly higher breast density on average than women who did not respond to the survey and did not develop a breast cancer. Thus, in women without breast cancer, responders were more at risk than non responders. Under these conservative conditions, we considered that the selection bias would not have penalized the analysis. Moreover, since women are not informed of the degree of 


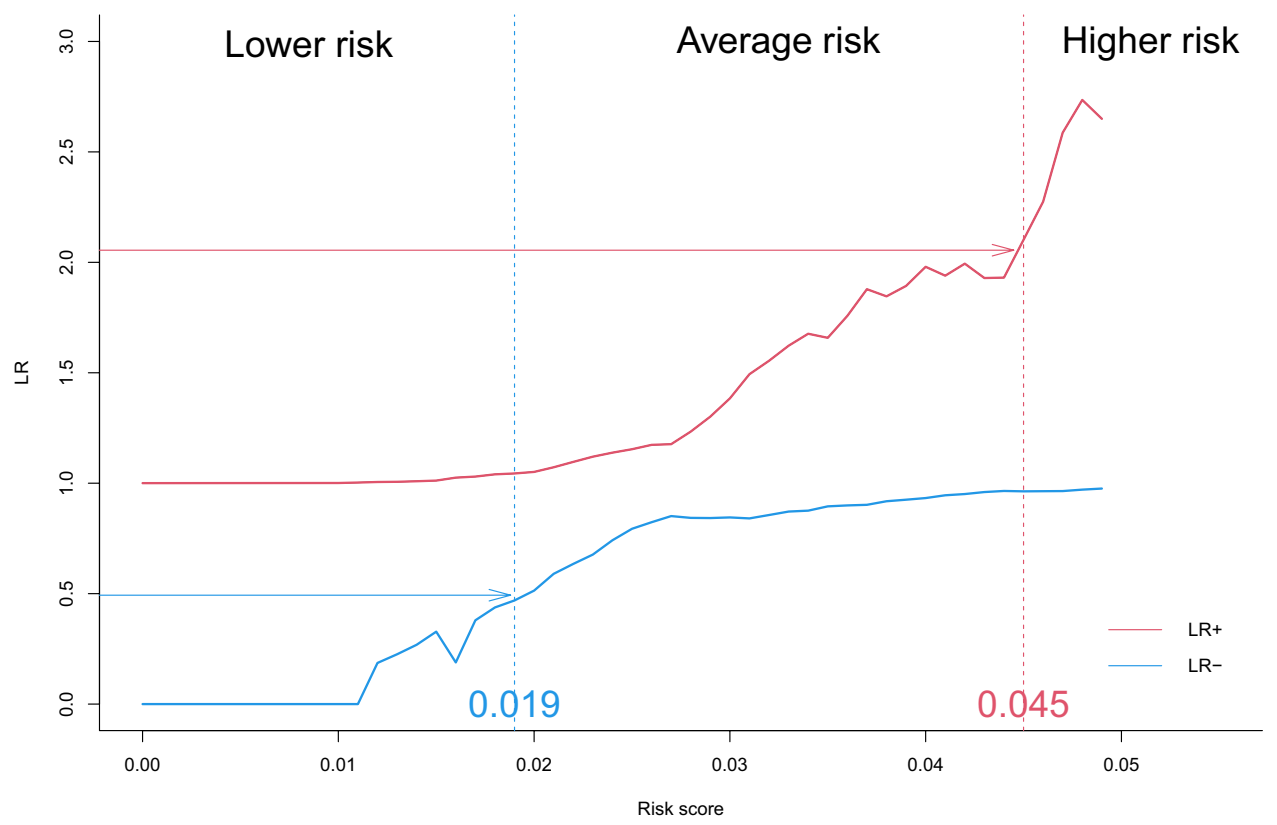

Figure 2. Determination of the three risk groups with optimal thresholds in women at average risk of breast cancer: "Lower risk", "Average risk" and "Higher risk".

their breast density, we did not retain the fact that breast density as such, might have been a criterion to answer the questionnaire, or not.

\section{Cox model.}

The final model, presented in Table 4, has been built with 2768 women for whom answers to all the covariates of the model were available, including 2241 non-cancer patients and 527 women who developed cancer during the follow-up period.

The risk factors selected by the model were high breast density (ACR BI-RADS grading) (B vs A: HR $=1.41$, $95 \%$ CI $[1.05 ; 1.9], \mathrm{p}=0.023 ; \mathrm{C}$ vs A: $\mathrm{HR}=1.65,95 \%$ CI $[1.2 ; 2.27], \mathrm{p}=0.02 ; \mathrm{D}$ vs A: HR $=2.11, \mathrm{CI}[1.25$; $3.58], \mathrm{p}=0.006)$, history of maternal breast cancer $(\mathrm{HR}=1.61,95 \% \mathrm{CI}[1.24 ; 2.09], \mathrm{p}<0.001)$, and socioeconomic difficulties ( $\mathrm{HR}=1.23,95 \% \mathrm{CI}[1.09 ; 1.55], \mathrm{p}=0.003)$. While early menopause ( $\mathrm{HR}=0.36,95 \% \mathrm{CI}[0.13 ; 0.99]$, $\mathrm{p}=0.003)$ and an age at menarche after 12 years $(\mathrm{HR}=0.77,95 \% \mathrm{CI}[0.63 ; 0.95], \mathrm{p}=0.047)$. Age $(\mathrm{HR}=1.024$, $95 \%$ CI $[0.997 ; 1.05], \mathrm{p}=0.084)$ and interaction between age at menarche and menopause $(\mathrm{HR}=2.73,95 \% \mathrm{CI}$ $[0.91 ; 8.19], \mathrm{p}=0.073$ ) have been forced in the model. The interaction between age at menarche and menopause was forced in the model to take into account the duration of estrogen impregnation, a notable risk factor in our literature searches ${ }^{28}$.

Bootstrap. We computed 100,000 bootstrap databases using random sampling with replacement among the 2768 women for whom we had answers to all the covariates of the final Cox model. The risk function $F(t)$ was calculated for all women in the 100,000 databases.

Threshold determination. Pre-test prevalence of the disease was the percentage of breast cancer in the CRCDC-OC database i.e. $2.6 \%$.

So, as described in Supplementary material 2, we looked for :

- $s_{1}$ such as $\forall s \geq s_{1}$ :

$$
L R_{+}(s) \geq 2.054
$$

- $s_{2}$ such as $\forall s \leq s_{2}$ :

$$
L R_{-}(s) \leq 0.493
$$

We then plot LR+(s) and LR-(s) in Fig. 2. We drew the lines $y_{1}$ and $y_{2}$ with respective equations $y_{1}=2.054$ and $y_{2}=0.493$. This made it possible to find $s_{1}$, which is the abscissa of the intersection point between $y_{1}$ and the representative curve of the $L R_{+}$function, and $s_{2}$, which is the abscissa of the intersection point between $y_{2}$ and the representative curve of the $L R_{-}$function. This method gave a low threshold at $1.9 \%$ and a high threshold at $4.5 \%$.

On one hand, $9.39 \%$ of women $(469,500$ women with a participation rate of 50\%) presented a 12 -year risk lower than $1.9 \%$. Among this group, the mean 12 -year risk was $1.37 \%$. On the other hand, $2.85 \%$ of women 


\begin{tabular}{|l|l|l|}
\hline & Mean 12-year risk & $\begin{array}{l}\text { Estimated number of targeted women in the organised BC } \\
\text { screening population (\%) }\end{array}$ \\
\hline Lower risk $(12$-year risk $<1.9 \%)$ & $1.37 \%$ & $469,500(9.39 \%)$ \\
\hline Average risk $(1.9 \% \leq 12$-year risk $\leq 4.5 \%)$ & $2.6 \%$ & $4,388,000(87.76 \%)$ \\
\hline Higher risk $(12$-year risk $>4.5 \%)$ & $5.84 \%$ & $142,500(2.85 \%)$ \\
\hline
\end{tabular}

Table 5. Distribution of the organised BC screening population according to the level of risk.

( 145,000 women with a participation rate of $50 \%)$ presented a 12 -year risk higher than $4.5 \%$ with a mean 12 -year risk of $5.84 \%$. All this results are presented in Table 5. Of note, if the BC screening participation rate rose to $65 \%$, that would almost represent 800,000 women with a risk different from the "average" risk.

\section{Discussion}

This work was dedicated to explore whether it was possible to offer a personalized risk based screening to the population of women at « average » risk of BC. In a retrospective cohort of French women, aged 50 to 60 , at « average » risk of breast cancer and followed-up for 12 years, from 2006 to 2018, who underwent the BC organized screening, we identified two additional levels of risk, either twice lower than the average-risk, or twice higher. Our partition into three groups at risk of breast cancer in these women showed that the level of risk in the socalled " average " risk population is not homogeneous.

In a first step we built a score of breast cancer risk that included six variables, two of which (age and breast density) were already included in the databases of the French CRCDCs. Only four more questions were required to be asked in order to establish the score. This information is easy and simple to collect at the time of the mammogram.

In a second step, based on the score and likelihood ratios, we identified three levels of risk with a risk ratio of at least 2 between the group at average risk and the group at lower risk on one hand, and on the other hand with the group at higher risk. It lead to fairly large group sizes. Thus, $12.3 \%$ of women belonged either to the lower risk group (9.4\%) or to the higher risk group (2.9\%). We chose to look for a risk divided or multiplied by a factor two. This choice remains arbitrary, though clinically relevant. Moreover, sensitivity analysis could be carried out by varying this ratio according to complementary hypotheses of epidemiologists or physicians specialized in these field. Furthermore, the choice could be supported by a cost function taking into account monetary cost and years of life adjusted for quality of life.

The levels of BC risk are difficult to compare between countries since the clinical guidelines where risk-based screening is recommended differ from country to country, or even in the same country for instance in the United States of America (USA). For the United Kingdom (UK) three levels of risk were delineated by the National Institute for Health and Care Excellence (NICE): near population risk, moderate risk and high risk ${ }^{29}$. The term used by the Nice guidelines of « moderate " $\mathrm{BC}$ risk is based on a lifetime risk from age 20 of developing breast cancer of at least $17 \%$ but less than $30 \%$. A moderate risk between ages 40 to 50 was estimated between $3 \%$ and $8 \%$. The recommendations on surveillance for women at moderate BC risk are modulated according to age. As the likelihood of getting breast cancer increases with age, all women aged from 50 to their 71 st birthday who are registered with a GP are automatically invited for breast cancer screening by mammography every 3 years (Guidance NHS Breast screening programme screening standards valid for data collected from 1 April 2021) (www.nhs.uk). The term " average » risk was retained by the National Comprehensive Cancer Network in the $\mathrm{US}^{30}$. For the NCCN Panel, increased risk of developing BC is defined by the modified Gail model for women $\geq 35$ years of age as a 5 -year risk of $1.7 \%$ or greater. The United States Preventive Services Task Force (USPSTF) recommends biennial screening mammography for women between the ages of 50 and 74 years ${ }^{31}$. However, the NCCN recommendations are different. For a woman aged 35 years of age or older, with a 5 -year risk $\geq 1.7 \%$ or greater, defined by the modified Gail model (bcrisktool.cancer.gov) the NCCN Panel encourages breast awareness and recommends a clinical encounter every 6 to 12 months and annual digital mammography, with the consideration of tomosynthesis.

In France, the term "average risk" refers here to the sub-population of women aged 50 to 70 years of age for whom BC screening is indicated, i.e. asymptomatic women who are not at « high risk» . The lifetime risk from age 20 of developing breast cancer in our population was $15.2 \%$. The terms « high risk » or " very high risk » are reserved for women presenting with known risk factors, particularly familial risk factors, or genetic factors such as BRCA-1-2. The Haute Autorité de Santé defined "high" or "very high" risk women ${ }^{4}$. Several contexts justify a specific exploration in women who already experienced a personal history of breast cancer, ductal or in situ lobular carcinoma or atypical lobular or ductal hyperplasia, in women who have had high dose medical chest irradiation (especially for Hodgkin's disease), and those who experienced some family history of BC. In the event of a BC family history with an Eisinger score equal or greater than 3, which leads to an oncogenetic consultation, AND in the absence of a BRCA 1 or 2 mutation in the family, it is the oncogeneticist that assesses the woman's personal risk of $\mathrm{BC}$. Women at « high risk» or « very high risk» benefit from individualized monitoring and are not integrated in the French organized BC screening.

Clinical Guideline CG164 for family history of BC were provided by the NICE entitled : classification, care and managing breast cancer and related risks in people with a family history of breast cancer ${ }^{32}$. The NCCN recommendations for Genetic/Familial High-Risk Assessment: Breast, Ovarian, and Pancreatic are also available ${ }^{33}$. 
Since we focused our study on women at average risk, we did not include information on genomics or susceptibility genes in our questionnaire. However, several studies ${ }^{12,34,35}$ targeted breast cancer susceptibility genes in order to better personalize the screening procedure. Moreover, two ongoing studies explore risk based screening strategies that include genomic tests and polygenic risk scores. The "WISDOM" study (Women Informed to Screen Depending On Measures of risk) is a multicenter trial comparing risk-based screening to annual screening in 100,000 women aged 40-74, initially launched in the Athena Breast Health Network in California and the Midwest ${ }^{36}$. It is based on personalized breast cancer screening recommendations based on individual risk assessments. Components of individual risk assessment are based on integral biomarkers: Breast Cancer Surveillance Consortium 5-year risk; genomic tests for rare high/moderate-penetrance mutations in a number of genes, including the following: BRCA1, BRCA2, ATM, CDH1, CHEK2, PALB2, PTEN, STK11 and TP53; and polygenic risk score from 96 lower-risk common genetic variants (SNPs) with known association to breast cancer, updated as data emerge. Two primary endpoints were defined: safety is explored through a non-inferiority hypothesis comparing the rate of stage IIB cancers or higher diagnosed in annual versus risk-based screening arms. Morbidity evaluation is based on a reduced rate of recall and breast biopsy between arms. Another ongoing study is «MyPebs » (My Personal Breast Screening) ${ }^{37}$ which is an international randomized, open-label, multicentric study assessing the effectiveness of a risk-based breast cancer screening strategy, which uses clinical risk scores and polymorphisms, compared to standard screening, according to the current national guidelines in each participating country, in detecting stage II or higher breast cancers. Women aged 40 to 70 years old are differentially screened for 4 years ${ }^{38}$.

The recruitment of WISDOM or MyPebs studies differ from our's. In our study, we included women aged 50 to 62 years, and followed-up for 12 years. Moreover, the French screening is not based on annual screening but on biennial mammogram. Moreover, unlike these two studies, we took into account all types of breast cancer and not just stage II or higher cancers.

In our study we did not include genomic tests, neither search for genetic variants. In our sample, only $1.5 \%$ of women of the lower risk group had a mother who presented a BC. It was $6.1 \%$ in the average group. Conversely, it was $71.7 \%$ in the higher risk group. We considered that genomic tests including 9 genes and 96 to 258 SNPs in women at average risk is not currently a screening approach that can be extended in France to 10 million women aged between 50 and 74 years. Moreover, the costs efficiency of such a strategy, financial as well as organizational, has not been evaluated yet. It is also worth noting that the penetrance of a particular pathogenic germline variant $(\mathrm{PGV})$ in a patient without a pretest probability that satisfies the National Comprehensive Cancer Network recommendations for targeted testing for that PGV, is unclear for most PGVs ${ }^{33}$. In effect, it remains difficult to estimate penetrance when a particular PGV is discovered in a woman who lacks a significant pretest probability of carrying this particular PGV ${ }^{39-41}$.

Women interviewed during the French citizen consultation on breast cancer screening in 2017, expected the organized screening to be more targeted ${ }^{42}$, thanks to advances in research, and to become more personalized according to individual risk factors. Physicians, also consulted, mentioned the value of determining the level of individual risk $^{7,43}$. They also ask for a score in French women in order to substantiate the levels of risk. In this perspective, we developed a user friendly computer application, mainly dedicated to physicians, that enables estimating the value of $\mathrm{BC}$ risk for a given woman, and provides an aid to personalizing the organized screening accordingly (application available at shiny.temas-bonnet.site/breast_cancer).

In France, the organized BC screening enables a regular follow-up of invited women, aged 50 to 74 , to get a biennial mammogram, covered by health insurance, in the radiology office of their choice. Moreover, even if the initial reading of the mammogram does not present any anomaly, a second reading is systematically performed by another radiologist. The second independent reading is a guarantee of reliability, with almost $8 \%$ of the breast cancers detected by the independent second reading ${ }^{44,45}$.

The principle of an organized breast cancer screening has been challenged given the claims of over-diagnosis or over-treatment (references). A reassessment of the organized screening that would allow a personalization according to the individual level of risk, would enable a standardized and quality monitoring of women, while producing evaluative data.

Depending on the presence or level of clinical, genetic or biological markers, treatment strategies are personalized to be as effective as possible. This approach can be extended to public health and in particular for primary and secondary prevention. Indeed, offering personalized prevention strategies could increase adherence to the the screening program, and effectiveness as well. Thus, identifying new groups at risk among women at average BC risk offers new perspectives. According to the two highlighted thresholds of lower and higher risk, $12 \%$ of women were thus identified, corresponding to more than 600,000 women in the French population. In this population at "average" risk of breast cancer, a new screening strategy might therefore be proposed for the groups at lower or higher risk. For the group at average-risk of breast cancer, corresponding to $88 \%$ of the presently screened population, the current screening rate, i.e. a mammogram every two years, would be maintained as such.

For the group at lower risk that includes $9.4 \%$ of the screened population with a level of risk of $1.37 \%$ of developing breast cancer within the 12 years of follow-up, we propose to reduce the frequency of mammograms with a mammogram every three or more years instead of the two years currently in force. This mammogram spacing could reduce the risk of over-diagnosis while maintaining a regular follow-up. Moreover, it would reduce, the risk of radiation-induced cancer, even if it is already very low. However, the risk of interval cancer can't be excluded. This proposal will have thus to be tested with an appropriate design.

For $2.9 \%$ of women at higher risk that we identified among women of our BC screening population, if they fulfill the criteria above defined by the Haute Autorité de Santét ${ }^{4}$ an oncogenetic consultation is required. Otherwise, particularly in the group of high breast density, increasing the frequency of mammograms is conceivable. However, high breast density is an important risk factor for this group where the distribution of high or very high breast density was $60 \%$ compared to $28 \%$ in the group at average risk and $3 \%$ in the group at lower risk. 
Furthermore, the mammogram sensitivity falls to $63 \%{ }^{46}$ for very dense breasts. The sensitivity of cancer detection via a mammogram appeared inversely proportional to breast density ${ }^{47}$. Thus, it did not seem that increasing the frequency of mammograms would bring a significant benefit. Based on recent results, an alternative would be to offer these women an abbreviated breast MRI, which appeared associated with a higher rate of breast cancer detection among women with dense breasts ${ }^{48}$, while maintaining a two-year frequency for surveillance.

Such a personalization of the organized screening might make women feeling more involved. For women at lower risk, a mammogram every three years would be less restrictive than every two years. For women at higher risk (excluding women for whom an oncogenetic consultation is indicated), offering an intensified surveillance may increase their adhesion to an adapted screening. This strategy might contribute to increase the participation of French women to the organized screening which is currently around $50 \%{ }^{5}$, although the target is $65 \%$.

As previously stated, the case finding costs (including diagnosis and treatment costs) should be economically balanced in connection with possible expenditure on medical care as a whole ${ }^{49}$. Analysis of the medico-economic gain should be carried out taking into account, among other things, interval cancers, over-diagnosis and the stage of detected BC. In this observational survey, the difficulty to contact women is inherent in this type of design and might introduce a selection bias. In our study, among non-participating women, 4 out of 5 were not reachable by phone, however it did not introduce a selection bias since it is at random. Conversely, 1 in 5 women indeed refused to answer the questionnaire which might have introduced a selection bias, even if the majority of them alleged a lack of time to fill out the questionnaire. We considered that it was not obviously linked to the level of $\mathrm{BC}$ risk, though limiting a potential selection bias.

An internal validation on another database, for example of women aged 40 to 50 in the Hérault department, would be of interest. External geographic validation might be carried out on the databases from other CDCRCs and/or a database from another country ${ }^{50}$. Moreover, information of interest for the creation of our score was collected at $t_{0}$, the inclusion time. But, over time, the value of variables retained at $t_{0}$ may change and the risk at $t_{0}+x$ years may also change. It will therefore be necessary to regularly re-estimate risk of $\mathrm{BC}$ in order to assign women to the appropriate group of risk. A re-evaluation of the score will also be necessary on regular time intervals to reappraise the coefficients estimated by the model in order to evaluate whether they would need to be adjusted. In this study, we proposed a new approach to personalize the organized screening by stratifying the risk within the population at "average" risk and currently considered as homogeneous. However, the results of this study remain to be confirmed in other contexts.

\section{Data availability}

The data used and analyzed during the current study are available from the corresponding author (EB).

\section{Code availability}

The code used during the current study is available from the corresponding author (EB).

Received: 14 January 2021; Accepted: 6 September 2021

Published online: 27 September 2021

\section{References}

1. Santé publique france. Sante publique france - Cancers. Tech. Rep. https://www.santepubliquefrance.fr/maladies-et-traumatism es/cancers. (2021).

2. Lefeuvre, D., Catajar, N., Le, C., Benjamin, B. \& Bousquet, P. J. Dépistage du cancer du sein : impact sur les trajectoires de soins. Tech. Rep., Institut national du cancer (2018). https://www.e-cancer.fr/content/download/238001/3268333/file/Depistage_du_ cancer_du_sein_impact_sur_les_trajctoires_de_soins_mel_20180608.pdf.

3. Jay, N., Nuemi, G., Gadreau, M. \& Quantin, C. A data mining approach for grouping and analyzing trajectories of care using claim data: The example of breast cancer. BMC Med. Informatics Decis. Mak.https://doi.org/10.1186/1472-6947-13-130 (2013).

4. Haute Autorité de Santé. Dépistage du cancer du sein en France : identification des femmes à haut risque et modalités de dépistage. Tech. Rep., HAS (2014). www.has-sante.fr.

5. Santé publique France. Taux de participation au programme de dépistage organisé du cancer du sein 2018-2019 et évolution depuis 2005. Tech. Rep., Santé publique France (2020). https://www.santepubliquefrance.fr/maladies-et-traumatismes/cancers/cancer-dusein/articles/taux-de-participation-au-programme-de-depistage-organise-du-cancer-du-sein-2018-2019-et-evolution-depuis-2005.

6. INCa. Plan d'action pour la rénovation du dépistage organisé du cancer du sein. Tech. Rep., Institut National du Cancer (2017). https://solidarites-sante.gouv.fr/IMG/pdf/plan-actions-renov-cancer-sein-2.pdf.

7. Cases, C. et al. Rapport du comité d'orientation sur le dépistage du cancer du sein. Tech. Rep., INCA (2016). http://www.conce rtation-depistage.fr/wp-content/uploads/2016/10/depistage-cancer-sein-rapport-concertation-sept-2016.pdf.

8. Gail, M. H. et al. Projecting individualized probabilities of developing breast cancer for white females who are being examined annually. J. Natl. Cancer Inst. 81, 1879-1886. https://doi.org/10.1093/jnci/81.24.1879 (1989).

9. Euhus, D. M. et al. Pretest prediction of BRCA1 or BRCA2 mutation by risk counselors and the computer model BRCAPRO. J. Natl. Cancer Inst. 94, 844-851 (2002).

10. Antoniou, A. C., Pharoah, P. P., Smith, P. \& Easton, D. F. The BOADICEA model of genetic susceptibility to breast and ovarian cancer. Br. J. Cancer 91, 1580-1590. https://doi.org/10.1038/sj.bjc.6602175 (2004).

11. Tyrer, J., Duffy, S. W. \& Cuzick, J. A breast cancer prediction model incorporating familial and personal risk factors. Stat. Med. 23, 1111-1130. https://doi.org/10.1002/sim.1668 (2004).

12. Evans, D. G. et al. Improvement in risk prediction, early detection and prevention of breast cancer in the NHS Breast Screening Programme and family history clinics: a dual cohort study. Programme Grants Appl. Res. 4, 1-210. https://doi.org/10.3310/pgfar 04110 (2016).

13. Pastor-Barriuso, R. et al. Recalibration of the Gail model for predicting invasive breast cancer risk in Spanish women: A populationbased cohort study. Breast Cancer Res. Treat. 138, 249-259. https://doi.org/10.1007/s10549-013-2428-y (2013).

14. McTiernan, A., Gilligan, M. A. \& Redmond, C. Assessing individual risk for breast cancer: Risky business. J. Clin. Epidemiol. 50, 547-556. https://doi.org/10.1016/S0895-4356(97)00013-9 (1997).

15. Wang, X. et al. Assessment of performance of the Gail model for predicting breast cancer risk: A systematic review and metaanalysis with trial sequential analysis. Breast Cancer Res.https://doi.org/10.1186/s13058-018-0947-5 (2018). 
16. R Core Team. R: A Language and Environment for Statistical Computing (2019).

17. Mørch, L. S. et al. Contemporary hormonal contraception and the risk of breast cancer. New Engl. J. Med. 377, 2228-2239. https:// doi.org/10.1056/NEJMoa1700732 (2017).

18. D’Orsi, C. J. \& Acr. 2013 ACR BI-RADS Atlas: Breast Imaging Reporting and Data System (American College of Radiology, 2014).

19. WHO. Global recommendations on physical activity for health (WHO Library Cataloguing-in-Publication Data, 2010).

20. Santé publique France (MILDECA). Nouvelles recommandations sur l'alimentation, y compris l'alcool, l'activité physique et la sédentarité | Mildeca. Tech. Rep. (2019). https://www.drogues.gouv.fr/actualites/.

21. Lalys, L. \& Pineau, J. C. Age at menarche in a group of French schoolgirls. Pediatr. Int. 56, 601-604. https://doi.org/10.1111/ped. 12296 (2014).

22. Volant, S. Un premier enfant à 28,5 ans en 2015: 4,5 ans plus tard qu'en 1974. INSEE Première 1642, 2015-2018 (2017).

23. Robert-Bobée, I. 2,1 enfants par femme pour les générations nées entre 1947 et 1963. Insee Focus. Avril (2015).

24. WHO. Planning Guide for national implementation of the Global Strategy for Infant and Young Child Feeding. Tech. Rep., WHO (2007). http://www.who.int/maternal_child_adolescent/documents/9789241595193/en/.

25. Collège National des Gynécologues et Obstétriciens Français. La ménopause. Tech. Rep. http://www.cngof.fr/ communiques-de-presse/108-menopause.

26. Labbe, E. et al. A new reliable index to measure individual deprivation: The EPICES score. Eur. J. Public Heal. 25, 604-609. https:// doi.org/10.1093/eurpub/cku231 (2015).

27. Breslow, E. N. Contribution to discussion of paper by D. R. Cox. J. R. Stat. Soc. Ser. B 34, 216-217 (1972).

28. Hamajima, N. et al. Menarche, menopause, and breast cancer risk: individual participant meta-analysis, including 118964 women with breast cancer from 117 epidemiological studies. Lancet Oncol. 13, 1141-1151. https://doi.org/10.1016/S1470-2045(12)70425-4 (2012).

29. NICE. Summary of recommendations on surveillance for women with no personal history of breast cancer moderate risk high risk age moderate risk of breast cancer. Tech. Rep. https://www.nice.org.uk/guidance/cg164/resources/educational-resource-fbc-surve illance-table-pdf-190125757.

30. Jacobs, L. et al. Breast cancer screening and diagnosis, version 3.2018. JNCCN J. Natl. Compr. Cancer Netw.https://doi.org/10.6004/ jnccn.2018.0083 (2018).

31. Siu, A. L. Screening for breast cancer: U.s. preventive services task force recommendation statement. Ann. Intern. Med. 164, 279-296. https://doi.org/10.7326/M15-2886 (2016).

32. NICE. Overview | familial breast cancer: classification, care and managing breast cancer and related risks in people with a family history of breast cancer | guidance | nice. Tech. Rep. https://www.nice.org.uk/guidance/cg164.

33. NCCN. Genetic/familial high-risk assessment: Breast, ovarian, and pancreatic. Tech. Rep. https://www.nccn.org/guidelines/guide lines-detail?category $=2 \&$ id $=1503$.

34. Evans, D. G. R. et al. Assessing individual breast cancer risk within the u.k. national health service breast screening program: A new paradigm for cancer prevention. Cancer Prev. Res. 5, 943-951. https://doi.org/10.1158/1940-6207.CAPR-11-0458 (2012).

35. Gabrielson, M. et al. Cohort profile: The karolinska mammography project for risk prediction of breast cancer (karma). Int. J. Epidemiol.https://doi.org/10.1093/ije/dyw357 (2017).

36. Esserman, L. J. The wisdom study: Breaking the deadlock in the breast cancer screening debate. NPJ Breast Cancer 3, 34. https:// doi.org/10.1038/s41523-017-0035-5 (2017).

37. Delaloge, S. MyPeBS Protocol n: UC-0109/1805. Tech. Rep. (2018). http://www.adecam.fr/mypebs/protocole_etude.pdf.

38. UNICANCER. My personalized breast screening clinicaltrials.gov. Tech. Rep. https://clinicaltrials.gov/ct2/show/NCT03672331.

39. Sorscher, S. Universal genetic testing to identify pathogenic germline variants in patients with cancer. JAMA Oncol.https://doi. org/10.1001/jamaoncol.2021.1002 (2021).

40. Couch, F. J. et al. Associations between cancer predisposition testing panel genes and breast cancer. JAMA Oncol. 3, 1190-1196. https://doi.org/10.1001/jamaoncol.2017.0424 (2017).

41. Obeid, E. I., Hall, M. J. \& Daly, M. B. Multigene panel testing and breast cancer risk: Is it time to scale down?. JAMA Oncol. 3 , 1176-1177. https://doi.org/10.1001/jamaoncol.2017.0342 (2017).

42. INCa. Avis de la conférence des citoyennes. Tech. Rep., INCa (2016). https://www.e-cancer.fr/content/download/159248/20304 96/file/Depistagecancersein-aviscitoyennes-mars2016.pdf.

43. INCa. Avis de la conférence des professionnels. Tech. Rep., INCa (2016). https://www.e-cancer.fr/content/download/159250/20305 14/file/Depistagecancersein-avisprofessionnels-mars2016.pdf.

44. Doutriaux-Dumoulin, I., Allioux, A., Campion, L., Meingan, P. \& Molina, L. Cancers détectés par le deuxième lecteur : analyse des données de la campagne de dépistage du cancer du sein en Loire-Atlantique, 2003-2005 (nouveau cahier des charges). J. Radiol. 1137, 1839-1910 (2007).

45. Thurfell, E. L., Lernevall, K. A. \& Taube, A. A. Benefit of independent double reading in a population-based mammography screening program. Radiology 191, 241-244. https://doi.org/10.1148/radiology.191.1.8134580 (1994).

46. Carney, P. A. et al. Individual and combined effects of age, breast density, and hormone replacement therapy use on the accuracy of screening mammography. Ann. Intern. Med. 138, 168-175. https://doi.org/10.7326/0003-4819-138-3-200302040-00008 (2003).

47. Drukteinis, J. S., Mooney, B. P., Flowers, C. I. \& Gatenby, R. A. Beyond mammography: New frontiers in breast cancer screening. https://doi.org/10.1016/j.amjmed.2012.11.025 (2013)

48. Comstock, C. E. et al. Comparison of abbreviated breast MRI vs digital breast tomosynthesis for breast cancer detection among women with dense breasts undergoing screening. JAMA - J. Am. Med. Assoc. 323, 746-756. https://doi.org/10.1001/jama.2020. $0572(2020)$.

49. Wilson, J. M. G. \& Jungner, G. \& World Health Organization. Principles and practice of screening for disease. Public Health Papers 34 (1968).

50. Iatrakis, G. et al. Manosmed University's Risk factor calculator for female breast cancer: Preliminary data. Rev. Clin. Pharmacol. Pharmacokinet. Int. Ed. 32, 23-27 (2018).

\section{Acknowledgements}

We thank all the professionals who contribute to the Hérault BC screening program, the members of the Centre Régional de Coordination pour le Dépistage des Cancers (CRCDC) Occitanie, and the members of the Hérault Cancer Registry. We also thank the reviewers for their very constructive comments.

\section{Author contributions}

All authors contributed to the study conception and design. Material preparation and analysis were performed by E.B. The first draft of the manuscript was written by E.B. and all authors commented on previous versions of the manuscript. All authors read and approved the final manuscript. 


\section{Funding}

This work was funded by the University of Montpellier and Nîmes University Hospital which supported Emmanuel Bonnet Ph.D. thesis. A complementary funding was obtained from the Fondation de l'Avenir for the implementation of the telephone survey.

\section{Competing interests}

The authors declare no competing interests.

\section{Additional information}

Supplementary Information The online version contains supplementary material available at https://doi.org/ 10.1038/s41598-021-98604-6.

Correspondence and requests for materials should be addressed to E.B.

Reprints and permissions information is available at www.nature.com/reprints.

Publisher's note Springer Nature remains neutral with regard to jurisdictional claims in published maps and institutional affiliations.

Open Access This article is licensed under a Creative Commons Attribution 4.0 International License, which permits use, sharing, adaptation, distribution and reproduction in any medium or format, as long as you give appropriate credit to the original author(s) and the source, provide a link to the Creative Commons licence, and indicate if changes were made. The images or other third party material in this article are included in the article's Creative Commons licence, unless indicated otherwise in a credit line to the material. If material is not included in the article's Creative Commons licence and your intended use is not permitted by statutory regulation or exceeds the permitted use, you will need to obtain permission directly from the copyright holder. To view a copy of this licence, visit http://creativecommons.org/licenses/by/4.0/.

(C) The Author(s) 2021 